\title{
PERMANÊNCIA E ÊXITO ACADÊMICO: contribuição da Política de assistência estudantil na UFPA, Campus de Altamira
}

\author{
Pricila Lysik Vieira ${ }^{1}$ \\ Regina Celi Alvarenga de Moura Castro ${ }^{2}$
}

\section{RESUMO}

Nesse artigo é apresentado um estudo bibliográfico, realizado no ano de 2017, com o principal objetivo de analisar a relação entre a assistência estudantil na Universidade Federal do Pará, Campus de Altamira e a permanência e êxito acadêmico dos estudantes benefiários dos auxílios disponibilizados ao estudante desse Campus. A análise dos dados foi realizada à luz dos pressupostos teóricos e metodológicos da Análise de Conteúdo. A assistência estudantil foi marcada por ações esparsas e pontuais, assumindo caráter assistencialista. Especificamente no Campus de Altamira os estudantes enfrentam dificuldades em receber os auxilios por falta de compreensão dos editais, insuficiência de vagas para atender as demandas e burocracias que envolvem o processo de inscrição. Esses fatores combinados ou isolados ocasionam um baixo número de estudantes atendidos no Campus de Altamira e contribuem para aumentar os índices de retenção e evasão nesse Campus.

Palavras-chave: PNAES. Ensino Superior. Permanência.

\section{PERMANENCE AND ACADEMIC SUCCESS: contribution of the Student}

\section{Assistance Policy at UFPA, Altamira Campus}

\begin{abstract}
This article presents a bibliographic study, carried out in 2017, with the main objective of analyzing the relationship between student assistance at the Federal University of Pará, Campus de Altamira and the permanence and academic success of the students benefiting from the aid made available to the student. The analysis of the data was carried out in light of the theoretical and methodological assumptions of Content Analysis. The student assistance was marked by sparse and punctual actions, assuming a welfare character. Specifically in the Campus of Altamira students face difficulties in receiving the aid due to lack of understanding of the calls for applications, insufficient vacancies to meet the demands and bureaucracies that inv olve the enrollment process. These combined or isolated factors cause a low

1 Graduanda em Pedagogia. Universidade Federal do Pará, Campus Altamira, Brasil. ORCID iD: https://orcid.org/ 0000-0002-8282-2811. E-mail: pricilalkv68@gmail.com

2 Mestre em Educação. Professora de Pesquisa Educacional, Faculdade de Educação Campus de Altamira Universidade Federal do Pará. ORCID iD: https://orcid.org/ 0000-00028963-3108. E-mail: reginacastro@ufpa.br
\end{abstract}


number of students attending the Campus of Altamira and contribute to increase the retention and dropout rates in this Campus.

Keywords: PNAES. Higher education. Permanence.

\section{PERMANENCIA Y ÉXITO ACADÉMICO: contribución de la Política de asistencia estudiantil en la UFPA, Campus de Altamira}

\section{RESUMEN}

En este artículo se presenta un estudio bibliográfico, realizado en el año 2018, con el principal objetivo de analizar la relación entre la asistencia estudiantil en la Universidad Federal de Pará, Campus de Altamira y la permanencia y éxito académico de los estudiantes beneficiarios de las ayudas disponibles al estudiante campus. El análisis de los datos fue realizado a la luz de los presupuestos teóricos y metodológicos del Análisis de Contenido. La asistencia estudiantil fue marcada por acciones escasas y puntuales, asumiendo carácter asistencialista. Específicamente en el Campus de Altamira los estudiantes se enfrentan a dificultades en recibir las ayudas por falta de comprensión de los edictos, insuficiencia de plazas para atender las demandas y burocracias que inv olucran el proceso de inscripción. Estos factores combinados o aislados ocasionan un bajo número de estudiantes atendidos en el Campus de Altamira y contribuyen a aumentar los índices de retención y evasión en ese Campus.

Palabras clave: PNAES. Enseñanza superior. Permanencia.

\section{INTRODUÇÃO}

Neste artigo é apresentado um estudo de caráter bibliográfico sobre a assistência estudantil (AE) na UFPA, Campus de Altamira. O estudo é vinculado ao projeto Pesquisa em Políticas Públicas no Ensino Superior Assistência Estudantil, Permanência e Evasão (PAEES) desenvolvido na Universidade Federal do Pará (UFPA), Campus de Altamira, cujo eixo norteador é a relação entre o trinômio: ampliação do acesso, permanência e evasão do estudante no ensino superior.

As discussões sobre assistência estudantil no ensino superior têm sido recorrentes (DUTRA; SANTOS, 2017; LADEIRA; MARTINS, 2015; MACIEL; SILVA; VELOSO, 2015) e revelam a importância das lutas travadas pela União Nacional dos Estudantes (UNE) a partir da década de 1960 e das discussões promovidas a partir da década de 1980 pelo Fórum Nacional de Pró-Reitores de Assuntos Comunitários e Estudantis (FONAPRACE) para a sua implantação 
como direito social e política pública. Direito social aqui concebido como direito constitucionalmente garantido, que provê condições materiais de sobrevivência, dentre eles, saúde, educação e trabalho, a todo cidadão brasileiro.

A política de assistência estudantil é definida pelo Fórum Nacional de Pró-Reitores de Assuntos Comunitários e Estudantis como sendo o "[...] conjunto de princípios e diretrizes que norteiam a implantação de ações para garantir o acesso, a permanência e a conclusão de curso de graduação dos estudantes das IFES, na perspectiva de inclusão social [...] (FONAPRACE, 2012, p. 63).

O Decreto 7.234 de 2010, que instituiu O Programa Nacional de Assistência Estudantil (PNAES) considera a assistência estudantil como conjunto de estratégias e ações voltadas a apoiar a permanência dos estudantes das IFES nas áreas de moradia, alimentação, transporte, saúde, esporte, cultura, inclusão digital e apoio pedagógico (BRASIL, 2010).

$\mathrm{Na}$ UFPA a AE se insere nas "políticas para o provimento e manutenção dos auxílios diretos (financeiros) e indiretos (prestação de serviços), condições necessárias à permanência de discentes na UFPA, na perspectiva do direito" (UFPA, 2017, p. 3).

Nesse estudo a assistência estudantil foi considerada como ação efetivada em instituições públicas de ensino superior, amparada legalmente ou por iniciativa da instituição, voltada a apoiar a permanência dos estudantes no âmbito acadêmico.

Cabe salientar que em decorrência das políticas voltadas à reestruturação das universidades federais e ampliação da oferta de vagas no ensino superior, que instituiu o Programa de Apoio a Planos de Reestruturação e Expansão das Universidades Federais (REUNI) por meio do Decreto $n^{\circ}$ 6.096/2007 e da política afirmativa, Lei $n^{\circ} 12.711 / 2012$, que dispõe sobre a reserva de vagas para estudantes de escolas públicas e oriundos de família de baixa renda, as IFES passaram a receber um grande número de estudantes provenientes de setores da população que eram excluídos desse 
contexto. Com isso, o PNAES passou a ser considerado o principal meio para contribuir com a permanência desses estudantes.

Nessa perspectiva, a questão que problematiza essa investigação foi assim delimitada: A política de assistência estudantil adotada no Campus de Atamira tem contribuído para a permanência e êxito acadêmico de estudantes desse campus? Essa indagação foi a norteadora desse estudo, que teve como principal objetivo analisar a relação entre a assistência estudantil no Campus de Altamira e a permanência e êxito acadêmico dos estudantes benefiários dos auxílios disponibilizados ao estudante.

Este artigo, além da introdução e das considerações, está organizado em quatro seções, a primeira destinada à apresentação da metodologia, a segunda na qual é apresentado o percurso histórico da assistência estudantil, desde a década de 1920 até o ano de 2017, na terceira seção são apresentados aspectos da implantação da assistência estudantil na UFPA e na quarta é problematizada sua implantação no Campus de Altamira.

\section{METODOLOGIA}

A partir da pesquisa bibliográfica que subsidiou essa investigação foi possível estabelecer aproximação com o objeto de estudo, identificar a trajetória histórica da assistência estudantil no ensino superior brasileiro, os autores que discutem o contexto de implantação do PNAES e obter dados sobre a AE na UFPA e no Campus de Altamira, proporcionando a problematização da sua efetivação nesse Campus.

Para Köche (2011, p. 122) a pesquisa bibliográfica permite "levantar o conhecimento disponível na área, identificando as teorias produzidas, analisando-as e avaliando sua contribuição para auxiliar a compreender ou explicar o objeto da investigação".

Também foi realizado um levantamento do aparato legal que norteou a assistência estudantil no contexto da educação superior brasileira.

Os dados foram analisados à luz dos pressupostos teóricos e metodológicos da Análise de Conteúdo referenciada em Bardin (2011). 
Buscamos contextualizar e interpretar as concepções de assistência estudantil, categoria analítica central desse estudo, a partir da análise e interpretação do conteúdo das mensagens "visando obter, por procedimentos sistemáticos e objetivos [...] indicadores que permitam a inferência de conhecimentos relativos às condições de produção/recepção destas mensagens" (BARDIN, 201 1, p. 49).

Dessa forma, compreendendo que legislações e documentos refletem o contexto social e político no qual foram produzidos, e por isso não são neutros, ao contrário traduzem concepções ideológicas, buscamos compreender a inserção e discussão sobre a AE no contexo educacional brasileiro, identificar concepções subjacentes à sua implantação e analisar sua contribuição para a permanência e êxito acadêmico do estudante do Campus de Altamira/UFPA.

\section{SÍNTESE DA TRAJETÓRIA DA ASSISTÊNCIA ESTUDANTIL NO ENSINO SUPERIOR BRASILEIRO}

A trajetória da assistência estudantil no Brasil foi marcada por diferentes contextos econômicos e políticos que influenciaram seu percurso até sua institucionalização em 2010, como política de Estado.

No decorrer desse processo a AE foi desenvolvida por meio de ações esparsas e pontuais, vindo a ganhar notoriedade lentamente na medida em que foi sendo inserida nas legislações, sobretudo como resultados das reivindicações de movimentos estudantis em prol de uma universidade pública igualitária e de qualidade.

Para fins didáticos o caminho percorrido pela AE no Brasil foi organizado em três fases: A primeira, compreendida entre a década de 1920, quando é identificada na literatura menção às primeiras ações de assistência ao estudante, até o fim do Regime Militar. A segunda que se inicia no contexto de Redemocratização do país, a partir da década de 1980 até o final do governo Fernando Henrique Cardoso (2003) e a terceira fase demarcada pelo início do governo Lula (2003) e que se estende até os dias atuais, no governo Temer. 


\section{Os primeiros passos da assistência estudantil no Brasil}

Não há na literatura brasileira um consenso sobre as primeiras ações de assistência estudantil no país. Andrés (2011) sugere que pode ter sido a concessão das "[primeiras] 'repúblicas' da Imperial Cidade de Ouro Preto, antiga Vila Rica e capital das Minas Gerais, que, no início do séc. XIX abrigavam os estudantes da Escola de Farmácia e da Escola de Minas", porém a autora, não confirma sua hipótese.

Ladeira e Martins (2015) e Maciel, Silva e Veloso (2015) reivindicam como sendo o marco inicial da assistência estudantil no Brasil a construção da primeira Casa do Estudante Brasileiro, em 1928 que, contraditoriamente, ficava localizada em Paris e recebia jovens da elite brasileira que iam estudar na França. Nesse sentido a assistência ao estudante era voltada para o atendimento de filhos das classes mais abastadas da sociedade.

Dutra e Santos (2017) identifiaram que em 1929 um grupo de estudantes fundou a Casa do Estudante do Brasil, na cidade do Rio de Janeiro. De iniciativa filantrópica privada, a casa era mantida por meio de doações, inclusive do governo federal (BRASIL, 1931). Sua criação representou uma importante ação assistencialista, pois os estudantes carentes passaram a contar com apoio de moradia e alimentação. Para os autores esse pode ser considerado o marco inicial da AE no Brasil.

Essas foram ações esparsas e não se configuravam ainda como iniciativas do Estado para promover condições de permanência dos estudantes no ensino superior, porém são as primeiras iniciativas de assistência ao estudante nesse nível de ensino, mencionadas na literatura brasileira.

A AE assume sua primeira nuance de legalidade ao ser previsto, na Constituição de 1934, em seu artigo 157, que "A União, os Estados e o Distrito Federal reservarão uma parte dos seus patrimônios territoriais para a formação dos respectivos fundos de educação" (BRASIL, 1934, p. 34). No parágrafo segundo desse artigo é determinado que parte do mesmo fundo seria destinada "para auxílios a alunos necessitados, mediante fornecimento 
grat vito de material escolar, bolsas de estudo, assistência alimentar, dentária e médica, e para vilegiaturas3" (BRASIL, 1934, p. 34).

Não é mencionado a quais níveis de ensino eram destinados os auxílios, mas há indícios que se refira também ao ensino superior, porém, não foram identificados estudos que indiquem a abrangência e materialização dessa determinação legal. Nesse período as inciativas de assistência ao estudante do ensino superior federal continuaram sendo realizadas de maneira informal, marcadas por ações isoladas, circunstanciais e fortemente relacionadas às questões sociopolíticas e econômicas do país (DUTRA; SANTOS, 2017, MACIEL; SILVA; VELOSO, 2015).

Na Constituição de 1946 a AE passou a ter um caráter obrigatório, determinado no artigo 172, segundo o qual "Cada sistema de ensino terá obrigatoriamente serviços de assistência educacional que assegurem aos alunos necessitados condições de eficiência escolar" (BRASIL, 1946, p. 37). Entretanto na legislação não consta orientações sobre como a assistência educacional deveria ser efetivada e não há indicadores sobre sua abrangência.

Contudo, na primeira Lei de Diretrizes e Bases da Educação Nacional, Lei $n^{\circ}$ 4.024, sancionada em 1961, pelo presidente João Goulart, é especificado seu artigo 90 como deveria se dar a assistência educacional:

Em cooperação com outros órgãos ou não, incumbe aos sistemas de ensino, técnica e administrativamente, prover, bem como orientar, fiscalizar e estimular os serviços de assistência social, médicoodontológico e de enfermagem aos alunos (BRASIL, 1961, p. 11).

Porém, ainda que tenha havido ordenamento legal na legislação que passou a reger o ensino brasileiro em todos os níveis, a assistência estudantil que deveria estar inserida no âmbito da assistência social não se consolidou como um direito efetivo nesse período.

Foi durante a Ditadura Militar, que teve início em 31 de março de 1964, em meio a intensos debates e manifestações em prol de melhorias para o

\footnotetext{
${ }^{3}$ Temporada que se passa fora do local de habitação original.
} 
ensino universitário que a UNE, nascida em 1938 como representação máxima dos estudantes do ensino superior, passou a organizar congressos e reuniões nos quais era salientada a necessidade de promoção de políticas destinadas a apoiar a permanência dos estudantes em suas graduações (DUTRA; SANTOS, 2017).

Apesar dos esforços da UNE não se observam grandes avanços em termos de assistência estudantil nessa fase, por isso a luta por direitos ao acesso e permanência nas universidades públicas continuou no centro das discussões dos estudantes e foi fortalecida a partir da década de 1980, a qual identificamos como segunda fase da AE no Brasil.

\section{Assistência estudantil no contexto de Redemocratização brasileira}

Em 1987, no contexto de Redemocratização do país, as reivindicações por assistência estudantil provenientes dos movimentos estudantis foram fortalecidas pela criação do FONAPRACE que congrega pró-reitores, sub-reitores, decanos ou responsáveis pelos assuntos comunitários e estudantis das Instit vições de Ensino Superior (IES).

Na Constituição Federal promulgada em 1988 é previsto em seu artigo 206 que o ensino fosse ministrado com base nos princípios de 1 "igualdade de condições para o acesso e permanência na escola" (BRASIL, 1988, p. 77). Todavia, não havia explicitação sobre ações que garantissem o acesso e permanência.

Em 1996 o artigo 206 da Constituição de 1988 é retomado na íntegra no artigo terceiro da atual Lei de Diretrizes e Bases da Educação, LDB 9.394/1996 reforçando a legalidade dos direitos sociais de acesso e permanência dos estudantes (DUTRA; SANTOS, 2017; FONAPRACE, 2012).

Nesse sentido a previsão de universalização do acesso e da igualdade de direitos em relação à permanência indicava a necessidade de uma política efetiva voltada à AE. Entretanto, Dutra e Santos (2017, p. 154) esclarecem que esse processo acontece em "meio a disputas de interesses e entraves políticos, de modo que as discussões acerca da política de AE 
ocorriam de forma fragmentada e restrita a algumas IFES, em sua maior parte, motivada pelos movimentos estudantis".

Dessa forma, no período de Redemocratização do Brasil também não é efetivada uma política de apoio à permanência do estudante no ensino superior, pois apesar de estar prevista na Carta Magna e na LDB 9.394/96, esses dispositivos legais foram insuficientes para garantir a implementação de uma política pública de AE em função da ausência de verbas destinadas para tal ação (VARGAS, 2008).

Com isso, a assistência estudantil continua marcada por ações isoladas, fragmentadas e sem garantia de direitos, prevalecendo seu caráter assistencialista, que marcou a AE no Brasil desde suas primeiras ações na década de 1920.

Foi nesse cenário de tentativa de efetiação de uma política pública de assistência ao estudante universitário que o FONAPRACE realizou entre os anos de 1996 e 1997 a primeira pesquisa junto as IFES brasileiras para traçar o perfil socioeconômico e cultural dos estudantes de graduação.

Foi identificado que $43 \%$ dos estudantes pertenciam as classes C, D e E, ou seja, eram provenientes de famílias com baixa renda, o que contribuía para um rendimento acadêmico insatisfatório, pois seus recursos financeiros não eram suficientes para custear suas necessidades básicas e muito menos para as despesas de cunho universitário (FONAPRACE, 2007).

Ainda foi identificado na mesma pesquisa que esses estudantes eram prejudicados pela falta de acesso a livros, a eventos culturais e que a vulnerabilidade socioeconômica era uma das causas de evasão e retenção no âmbito das universidades. Esses dados contribuíram para demonstrar a real necessidade de uma política de assistência estudantil na perspectiva de inclusão social.

No ano de 1999, após muitas discussões entre o FONAPRACE e os órgãos governamentais, e estudos que indicavam a necessidade de promoção de políticas para contribuir com a igualdade de oportunidades e a garantia de permanência dos estudantes em situação de vulnerabilidade socioeconômica nas IFES, O FONAPRACE garantiu a inclusão da assistência 
estudantil no Plano Nacional de Educação que teve vigência no decênio 2001-2010, no qual foi previsto em seu artigo 4, meta 34:

Estimular a adoção, pelas instituições públicas, de programas de assistência estudantil, tais como bolsa-trabalho ou outros destinados a apoiar os estudantes carentes que demonstrem bom desempenho acadêmico (BRASIL, 2001, p. 26).

Uma crítica a essa meta é a visão discriminatória de assistência ao estudante "com bom desempenho". A falta de assistência, segundo o FONAPRACE (2007), é um fator que acarreta o baixo desempenho, indicando contradição na inserção da AE no Plano Nacional de Eucação, que não adotou as orientações do FONAPRACE na íntegra, gerando dist orções no que tange à sua legalidade.

Após essa inserção, foi elaborada a minuta do primeiro Plano Nacional de Assistência Estudantil com base nos dados obtidos na pesquisa publicada pelo FONAPRACE em 1997. A versão final do documento foi enviada em abril de 2001 à Associação Nacional dos Dirigentes das Instituições Federais de Ensino Superior (ANDIFES) e passou a ser usada como referência no desenvolvimento de projetos e programas de assistência aos estudantes das universidades (FONAPRACE, 2012).

O objetivo do FONAPRACE com a implantação de um Plano Nacional de Assistência Estudantil consistia em

[...] incluir verbas específicas destinadas à assistência estudantil, na matriz orçamentária do MEC, para cada IFES; elaborar projetos especiais para recuperação e ampliação da capacidade instalada nos ambientes destinados à assistência; estabelecer a vinculação entre ações de acesso e programas de permanência e consolidar um Plano Nacional de Assistência (FONAPRACE, 2012, p. 26).

Entretanto apesar da orientação do FONAPRACE para a sistematização da assistência nas IFES, essa ação não era efetivada em todas as universidades nos moldes propostos, uma vez que, a AE não tinha se instituído como programa de Estado, o que viera a acontecer no contexto de implantação do REUNI, caracterizando a terceira fase da assistência estudantil no Brasil. 


\section{A formalização da assistência estudantil por intermédio do PNAES}

Na primeira gestão do governo Lula da Silva (2003-2006) foi instituído o Plano de Reestruturação e Expansão das Universidades Federais, por meio do Decreto n 6.096, de 24 de abril de 2007.

Como resultado da expansão, foram criadas 14 universidades federais e 104 campi, totalizando ao final de 2013, 237 municípios atendidos pelas universidades. Isso elevou o número de vagas ofertadas em cursos presenciais de graduação de 132.451, em 2007, para 146.762 ao final de 2008, o que representa 14.311 novas vagas (BRASIL, 2009), configurando-se, dessa forma, como a maior iniciativa do governo federal para a ampliação da oferta de vagas em universidades federais (ARAÚJO, 2011; ZAGO; PEREIRA; PAIXÃO, 2015).

Nesse cenário de ampliação do acesso ao ensino superior, o Plano Nacional de Assistência Estudantil foi atualizado pelo FONAPRACE, prevendo a assistência ao estudante por meio do desenvolvimento de atividades de ensino, pesquisa e extensão nas IFES. Em 2007 o PNAES tornan-se política de governo, por meio da Portaria Normativa n 39/2007 (FONAPRACE, 2011), indicando o primeiro passo para que se tenha no ensino superior brasileiro a consolidação de uma política de assistência estudantil.

Ainda que algumas reivindicações dos movimentos estudantis e do FONAPRACE, constantes na minuta do Plano Nacional de Assistência Estudantil não tenham sido incorporadas pelo governo, não se pode deixar de considerar a relevância do PNAES para a "ampliação e democratização das condições de acesso e permanência dos jovens na faixa etária de 18 a 24 anos no ensino superior" (FONAPRACE, 2012, p. 31).

As contribuições do PNAES para reduzir a retenção e melhorar as condições de permanência dos estudantes no ensino superior foram avaliadas positivamente pelo MEC e resultaram em maiores investimentos de recursos financeiros destinados a assistência estudantil (FONAPRACE, 2012).

Em julho de 2010 o PNAES foi convertido em Programa Nacional de Assistência Estudantil por meio do Decreto $n^{\circ} 7.234$, mantendo a sigla PNAES, e constituindo-se em programa de Estado, indicando uma vitória para todos 
os setores que lutaram para a consolidação legal da política de assistência estudantil no país.

Na análise de Carvalho (2015b) a luta do movimento estudantil e do FONAPRACE, associado ao processo de ampliação do número de vagas nas universidades públicas, proposto pelo REUNI, foi o que possibilitou a efetivação da AE como política de Estado.

De acordo com o PNAES, os programas de AE desenvolvidos nas IFES devem ser destinados, prioritariamente, aos estudantes "oriundos da rede pública de educação básica ou com renda familiar per capita de até um salário mínimo e meio" (BRASIL, 2010, p. 2, grifo no original), resgatando sua abrangência prevista na Minuta do FONAPRACE que havia sido restringida no PNE 2001-2010 ao indicar que a assistência seria somente a "[...] estudantes carentes que demonstrassem bom desempenho acadêmico" (BRASIL, 2001, p. 26, grifo nosso).

Em conformidade com o artigo segundo do Decreto $n^{\circ} 7.234 / 2010$ são objetivos do PNAES:

I- democratizar as condições de permanência dos jovens na
educação superior pública federal; II-minimizar os efeitos das
desigualdades sociais e regionais na permanência e conclusão da
educação superior; III - reduzir as taxas de retenção e evasão; e IV -
contribuir para a promoção da inclusão social pela educação
(BRASIL, 2010, p. 1).

Para alcançar esses objetivos o PNAES propõe que os recursos de assistência ao estudante sejam aplicados em dez diferentes áreas: I moradia estudantil; II - alimentação; III - transporte; IV - atenção à saúde; V inclusão digital; VI - cultura; VII - esporte; VIII - creche; IX apoio pedagógico; e X - acesso, participação e aprendizagem de estudantes com deficiência, transtornos globais do desenvolvimento e altas habilidades e superdotação (BRASIL, 2010).

A partir da instituição do PNAES como política de Estado a AE passa a ser regida por um Programa nacional que além de orientar as IFES em relação ao desenvolvimento de ações e projetos de apoio ao estudante também passa a destinar verbas para esse fim, sendo delegada às 
instituições autonomia para administrar os recursos repassados pelo Programa, bem como, definir os critérios e a metodologia de seleção dos estudantes (BRASIL, 2010).

Segundo Carvalho (2015b, p. 173) é nesse contexto que ocorre uma mudança expressiva nessa aréa

[...] que até então era desenvolvida com recursos direcionados ao custeio e ficava à margem das prioridades estabelecidas no orçamento das instituições, em conformidade com as concepções de assistência predominantes no âmbito de cada gestão.

De acordo com o FONAPRACE (2012) os recursos investidos em assistência estudantil foram crescentes entre os períodos de 2008 a 2012 , tendo elevado de $R \$ 125,3$ milhões em 2008 para $R \$ 504$ milhões em 2012. De acordo com o MEC em 2017 foram liberados mais $R \$ 1,2$ bilhão para a $A E$ nas universidades e institutos federais em todo o país (BRASIL, 2017).

Cabe salientar que após o início do governo TEMER, em maio de 2016 o PNAES sofreu cortes orçamentários, a propósito do que vem ocorrendo no ensino superior e em vários setores sociais. A pesar da retração orçamentária, - PNAES ainda se constitui como o Programa que tem garantido a permanência de muitos estudantes que há alguns anos eram alijados do ensino superior.

\section{A ASSISTÊNCIA ESTUDANTIL NA UFPA}

A Universidade Federal do Pará foi criada em julho de 1957 com atividades ofertadas somente na capital Belém. Atualmente a UFPA é composta por 11 campi, se configurando como uma das maiores universidades multicampi do país.

No período de sua criação a UFPA não possuía uma política de assistência estudantil consistente, mesmo assim, mediante esforços, em 1960, criou a primeira Casa de Estudantes da instituição para abrigar os discentes que não residiam em Belém e não tinham condições de arcar com despesas de moradia. 
Posteriomente, na década de 1990, é construído em Belém o primeiro Restaurante Universitário o qual se constituiu em grande apoio aos estudantes em relação à garantia de alimentação.

Em 2007 a Universidade Federal do Pará aderiu ao REUNI. Nesse mesmo ano sua política de assistência estudantil é fortalecida, pois, em função da instituição do PNAES, passa a receber verbas destinadas exclusivamente para esse fim.

Porém, somente no ano de 2017 a UFPA passa a ofertar macroprogramas de assistência ao estudante, oferecendo auxílios financeiros (auxílios diretos) ou atendimentos por meio de serviços (auxílios indiretos).

Os benefícios disponibilizados por meio de auxílio financeiro, são caracterizados na UFPA como sendo da dimensão de assistência: i) Programa Permanência (PP); ii) - Casa de Estudantes Universitários (PROCEUS); iii) - Programa Bolsa Permanência do Mistério da Educação (PBP/MEC).

De acordo com critérios estabelecidos pela UFPA, o auxílio Permanência pode ser acumulado com os auxílios Moradia, Creche, Kit Acadêmico, Acesso à Línguas Estrangeiras, Instruir e Taxa Zero, ou seja, o estudante pode adquirir até dois desses auxílios concomitantemente.

A assistência ao estudante disponibilizada por meio de serviços é caracterizada como dimensão de integração estudantil e oferta: i) Apoio Pedagógico (PROAP); ii) - Estudante Saudável (PES), que disponibiliza o atendimento aos estudantes nos hospitais universitários e/ou clínicas e instituições conveniadas e iii) - Programa Bolsa Acadêmica Permanência (PROBOLSA), que são disponibilizados por meio de programas e projetos em parceria com outros departamentos da UFPA.

Segundo informação do Sistema Gerencial de Assistência Estudantil (SIGAEST/UFPA), quando o estudante tem sua solicitação de auxílio deferida, passa a ter seu desempenho acadêmico acompanhado por profissionais desse setor. Este acompanhamento foi uma das reivindicações do 
FONAPRACE, quando se deram as negociações para tornar o PNAES uma política de Estado:

- estabelecer indicadores para pontuar a oferta dos serviços em relação ao atendimento e à demanda;

- avaliar a melhoria do desempenho acadêmico do estudante usuário da assistência [...] (FONAPRACE, 2012, p. 70).

Porém, apesar de haver dados no sistema que indicam como foi o rendimento quantitaivo do estudante semestre a semestre, não há dados sobre um acompanhamento pedagógico a estudantes beneficiados que apresentam dificuldades. Sobre esse aspecto não há registros e/ou relatórios, a propósito do que é sugerido pelo FONAPRACE.

\section{ASSISTÊNCIA ESTUDANTIL NO CAMPUS DE ALTAMIRA}

O Campus de Altamira, situado na região Sudoeste do Pará, também conhecida como região da Transamazônica e Xingu, foi criado em 1987 ofertando inicialmente cursos com turmas intervalares de Licenciatura. Na década de 1990 foram criadas as primeiras licenciaturas em regime regular (UFPA, 2016a). Atualmente o campus, oferta dez cursos em regime regular, sete cursos de licenciatura e três de bacharelado e atende mais de 1300 estudantes.

O perfil dos estudantes, que tem sido recorrente desde a instituição do campus, indica que a maior parte é potencial beneficiária do programa de $A E$, uma vez que em sua maioria os estudantes são oriundos de família de baixa renda, sendo a principal atividade produtiva das famílias, a agricultura de pequeno porte. Muitos desses estudantes deixaram sua cidade de origem para residir em Altamira, seja do estado do Pará ou de outros estados (SILVA et al., 2017).

Esse perfil indica uma grande demanda por assistência estudantil. Contudo, de acordo com Correa Neto (2016) somente em 2008, iniciaram no Campus os primeiros programas de auxílio aos estudantes. Porém, não há registro no Campus de Altamira que indique os benefícios concedidos nesse período e nem quantos foram os beneficiados. 
Em 2009 foram identificados benefícios concedidos nesse ano a alguns estudantes: implantação da Casa do Estudante Universitário com 30 vagas disponíveis; lançamento dos primeiros editais nos quais alguns estudantes passaram a ser contemplados com o auxílio Kit Acadêmico e visitas técnicas realizadas de maneira esporádica por psicólogos e assistentes sociais da equipe do Campus de Belém (UFPA, 2009). Além do número de vagas destinadas à casa do estudante, 30, não há registro de quantas kits de auxílio acadêmico foram disponibilizados e como foi o critério de seleção e nem de quais cursos são os estudantes contemplados.

Neste período a assistência estudantil era vinculada à Divisão de Extensão do Campus de Altamira, sem que houvesse nenhum setor específico para atendimento ao estudante.

A partir de setembro de 2014 houve a insercão de uma pedagoga na Divisão de Extensão do Campus, a qual assumiu dentre outras atribuições, o atendimento aos estudantes que se submetiam aos editais. Contudo, de maneira geral, era um atendimento pontual com vistas a solucionar dúvidas em relação à compreensão do edital, já que essa era uma das grandes dificultadas enfrentadas pelos estudantes quando se candidatavam aos auxílios.

A compreensão dos editais, que nem sempre são claros em relação à documentação necessária, ocasionava (e ocasiona) o indeferimento de muitos estudantes e a falta de clareza quanto à interposição de recursos impedia (e impede) que muitos desses estudantes, potenciais beneficiários, não recebam o auxílio.

As dificuldades relacionadas aos editais são reconhecidas pela SAEST, que segundo responsáveis por esse setor, têm promovido esforços para solucioná-las. O auxílio da pedagoga que ficou no campus até o ano de 2016 e atualmente de uma assistente social e de uma psicóloga tem contribuído para amenizar essas questões.

Esse não é o único problema enfrentado no campus pelos estudantes que demandam algum tipo de assistência para dar continuidade e concluir os estudos. Muitos problemas enfrentados são de ordem operacional, outros 
são de ordem pessoal ou institucional que em alguma medida comprometem a permanência do estudante do Campus de Altamira.

Dentre os problemas de ordem operacional são destacados:

i) Todas as etapas que envolvem o processo de aquisição do auxílio (planejamento, oferta, avaliação das inscrições e acompanhamento dos estudantes assistidos) estão centralizadas em Belém, Campus polo da UFPA. Esse fato ocasionou e ocasiona em muitos campi do interior dificuldades no estabelecimento da assistência estudantil, como ocorre no Campus de Altamira.

Atualmente há no Campus de Altamira um setor de assistência estudantil vinculado à SAEST, composto por uma assistente social e uma psicóloga. A implantação desse setor tem sinalizado para possíveis melhorias em termos de acesso aos programas, uma vez que essa equipe tem atendido discentes, tanto no que diz respeito à orientação sobre benefícios e seus direitos a tais benefícios, como atendimentos psicológicos e na realização de avaliações pela assistente social da situação socioeconômica do estudante para dar celeridade ao processo de efetivação de benefícios solicit ados.

Entretanto, a falta de autonomia desse setor em decidir sobre o deferimento ou indeferimento da solicitação do estudante, já que é vinculado a Belém, faz com que esse processo continue burocrático e demorado, o que em alguns casos emergenciais pode se tornar falho e assim insuficiente para evitar que o estudante evada, como já ocorreu e é destacado na pesquisa de Souza e Castro (2017) que identificaram que estudantes evadiram em função da demora e burocracia para a concessão de auxílios principalmente emergenciais que "não foram concedidos a tempo de evitar a evasão, indicando que questões burocráticas interferem na concessão de benefícios, contribuindo para o aumento do número de estudantes evadidos (SOUZA; CASTRO, 2016, p. 12).

ii) Muitos estudantes de Altamira apresentavam dificuldades de obter informações sobre os auxílios por questões de problemas com divulgação no Campus, uma vez que o acesso a internet na época em que teve início a 
assistência estudantil era precário na região (SILVA, et al., 2017). Esse problema permanece, ainda que de maneira mais atenuada.

iii) Toda documentação necessária para submissão aos editais é realizada on line, enviada à SAEST. Posteriormente deveriam ser realizadas entrevistas e visitas domiciliares, por profissionais da assistência estudantil de Belém (psicólogo e assistente social) "para melhor apreender a realidade social do discente e de sua família, permitindo melhor dimensionar a história de vida de cada estudante com diagnóstico familiar" (PINHEIRO, 2014, p. 9), porém essas entrevistas eram realizadas esporadicamente, o que contribuiu para o indeferimento de muitos estudantes que se encontram em situações de vulnerabilidade socioeconômica.

iv) O número de beneficiados está aquém do número de estudantes que demandam por algum tipo de auxílio no Campus de Altamira. Segundo dados do SIGAEST, em 2016, foram beneficiados no Campus de Altamira 51 discentes contemplados com os auxílios Permanência Intervalar (17), Casa de Estudantes (8), Permanência (13), Moradia (7), Língua estrangeira (1), Emergencial (3), Permanência MEC (1) e Creche (1) (UFPA, 2016b).

Esse número não representa $5,0 \%$ dos estudantes matriculados no período. Considerando o perfil socioeconômico dos estudantes do campus, que em sua maioria é de baixa renda, pode-se afirmar que menos de 5,0\% dos estudantes que estão de acordo com o perfil de vulnerabilidade econômica, indicado pelo Reuni e pelo PNAES, não foi contemplada no ano de 2016. Sobre anos anteriores não há registro na instituição.

v) A vigência dos auxílios é de um ano podendo o aluno solicitar renovação, por meio do edital aberto anualmente. Um dos grandes problemas para muitos estudantes é a não garantia de obtenção do recurso durante o período regular de integralização do seu curso. Esse fator causa preocupação ao estudante atendido, por não saber se terá condições financeiras para concluir o ensino superior. Pinheiro (2016) faz uma análise sobre essa situação 
Assim, pode-se refletir quais os elementos que estão presentes na política de assistência estudantil na UFPA [...]. Este é tomado por um viés fragmentador e seletivo, afinal, a assistência ao estudante na UFPA é materializada pela concessão de auxílios que são disputados ponto a ponto por meio de um processo seletivo, que põe a prova o grau de pobreza, privação e vulnerabilidades que os estudantes estão expostos, sendo tais elementos identificados e mensurados de acordo com características que "desconstrói a construção histórica" do "direito a ter direitos" (PINHEIRO, 2016, p. 109 - 110).

A análise de Pinheiro corrobora com nossa análise sobre a assistência estudantil praticada na UFPA e nas demais IFES brasileiras, de que tem prevalecido o caráter assistencialista da concessão de recursos, caracterizando a privação do direito subjetivo, previsto na Constituição em relação à permanência e conclusão do ensino superior.

vi) Não há dados específicos disponíveis para consulta que permitam a identificação de quantos e quais auxílios foram disponibilizados em cada campi, assim como quantos estudantes foram beneficiados por cada auxílio. Porém os dados do Campus de Altamira sinalizam para a assimetria em relação à distribuição de auxílio da assistência estudantil entre o campus polo e os campi do interior, uma vez que o maior quantitativo de benefícios e maior variedade são ofertados no campus polo.

Um dos motivos dessa assimetria pode estar relacionado com a forma de seleção dos estudantes já indicada e a baixa abrangência da assistência em face ao grande número de estudantes que apresentam vulnerabilidade socioeconômica:

a seletividade e precariedade da assistência estudantil nas universidades federais brasileiras, por seu turno, colocam em xeque o sucesso da trajetória acadêmica dos alunos de graduação, especialmente daqueles oriundos das camadas sociais menos favorecidas econômica e culturalmente, resultando na evasão e/ou retenção de um percentual significativo desses estudantes (CARVALHO, 2015b, p. 171).

A indefinição de ter o auxílio garantido, mesmo que preencha requesito como bom coeficiente acadêmico, gera preocupação no estudante, que em alguns casos se agrava para adoecimento emocional. 
Sobre os problemas de ordem pessoal e/ou institucional são identificados:

i) Dados empíricos de pesquisa em andamento no Campus de Altamira, com o objetivo de levantar o percentual de estudantes dos cursos regulares com ingresso entre os anos de 2013 e 2016 que foram beneficiados pela assistência estudantil, revelam o baixo índice de estudantes beneficiados, não atingindo $15,0 \%$ do total de potenciais beneficiários.

Esse dado é preocupante, pois considerando o perfil dos estudantes do Campus de Altamira, além da assistência financeira que necessitam e muitos não recebem, há demandas para assistência à saúde mental do estudante e assistência pedagógica, ambas previstas no PNAES e ofertadas somente no campus polo.

ii) Muitos estudantes residem fora do município de origem, já que se mudaram para Altamira para estudar. $O$ afastamento do ambiente familiar pode gerar problemas afetivos e emocionais que comprometem sua saúde mental e a trajetória acadêmica. Poblemas dessa ordem foram identificados por Adachi (2009); Almeida e Schimiguel (2011) em estudos realizados sobre evasão do estudante universitário em outros contextos. Nos estudos é indicado que os estudantes que moram distante da família, demandam em sua maioria de assistência psicológica e/ou psiquiátrica. Esse tipo de assistência ainda é incipiente no Campus de Altamira.

iii) Grande parte dos estudantes é oriunda de escolas públicas e apresenta dificuldades de aprendizagem acarretadas por ter cursado um Ensino Médio deficitário. A dificuldade em acompanhar o ritmo universitário em função da precariedade do Ensino Médio também foi identificada por Adachi (2009) e Sampaio, et al. (2011) em seus estudos, indicando serem esses alguns dos ocasionadores do abandono dos estudos pelo estudante do ensino superior.

Programas de nivelamento são recomendados para atenuar as dificuldades dos estudantes. Programa desse tipo é ofertado no campus polo e já foi ofertado no Campus de Cametá, por iniciativa de um professor (RIBEIRO; SILVA; CASTRO, 2017), e também por iniciatica de um professor no 
Campus de Altamira nos anos de 2013 e 2014, não sendo constatado demais programas de nivelamento no campus.

A assimetria em relação à distribuição de benefícios, como já discutido, acarreta muitos problemas para o estudante que não é beneficiado. Muitas mães estudantes abandoram o curso por não terem o auxílio creche. Por não terem condições financeiras de prover uma creche ou alguém que tome conta dos seus filhos quando estudam, optaram por abandonar os estudos.

Dificuldades em adquirir material necessário ao curso, falta de benefício para custear participação em eventos, falta de restaurante universit ário e poucas vagas na casa do estudante, também são fat ores que têm levado muitos estudantes a desistir do curso e abadonar o ensino superior.

Atrelado a todos esses problemas, soma-se fatores de ordem pedagógica, que também leva o estudante a elavado grau de estresse, senão à evasão.

Em função de ter sido identificada por uma professora da Faculdade de Educação do campus, alta demanda para assistência ao estudante e a ausência de um setor que tivesse como objetivo atender aos estudantes que demandassem atendimento pedagógico e psicológico, no ano de 2013 foi instituído em caráter voluntário o Projeto de Apoio Pedagógico e Psicológico (PASES) por essa professora, por meio da Portaria 265/2013.

A alta demanda para atendimento no PASES indicou a necessidade de ampliação da equipe que em 2014 contava com uma pedagoga e uma psicóloga. Em 2017 compunha a equipe além da pedagoga que coordena o projeto, seis psicólogos e uma psiquiatra, sendo somente a pedagoga, uma psicóloga e a psiquiatra, professores efetivos do campus. Os demais especialistas prestam atendimento clínico voluntário por serem sensíveis a alta demanda de atendimento à saúde mental no ensino superior.

$\mathrm{Na}$ área pedagógica são prestados atendimento individuais, em pequenos grupos, ou em formato de oficina, de acordo com demandas apresentadas pelos estudantes do campus. 
A alta demanda para atendimento na área pedagógica e psicológica, corrobora com a literauta que tem discutido as demandas de assistência estudantil no ensino superior e sua ausência como agravante da evasão nesse nível de ensino. Nesse sentido, o baixo índice de estudantes beneficiados no Campus de Altamira tem contribuído para o agravo nos índices de evasão e retenção.

Estudo realizado em 2017 sobre indicadores educacionais no Campus de Altamira (CASTRO; SILVA, 2017) demonstrou a necessidade de implementação de políticas internas para promover condições de permanência e conclusão dos cursos, pelo fato de o campus apresentar, ano após ano, evasão média acima da média nacional, que tem sido próximo a $25 \%$ e alto índice de estudantes que não concluem o curso no período regular.

Estudos já realizados no Campus a respeito da evasão (CORREA NETO, 2016; CASTRO, 2017; SOUZA; CASTRO, 2017; SOUZA, 2017; TEIXEIRA, 2016) que diretamente se relacionam às políticas de assistência estudantil, indicam que essa política ainda é deficitária, tanto em âmbito nacional, como local, o que tem contribuído sobremaneira para um alto índice de evasão no Campus de Altamira.

Para Correia Neto (2016, p. 49-50),

[...] é preciso que haja além da manutenção da assistência ao estudante, a ampliação e potencialização dos programas assistenciais, que visem atender às demandas do alunado nos mais variados aspectos, sejam estes físicos, psicológicos, pedagógicos, profissionais ou econômicos.

De maneira geral a assistência estudantil na UFPA e no Campus de Altamira, não tem sido suficiente para impedir altas taxas de evasão, e promover possibilidades de permanência no ensino superior a todos os estudantes que necessitam de auxílio para esse fim, contudo tem contribuído para atenuá-la. Segundo Vargas (2008), esse fato se deve, sobretudo, porque ao longo de seu percurso histórico a AE ocupou posição periférica nas legislações brasileiras, como atestado nesse artigo. 
Apesar dos avanços em termos de legislação e recursos, ainda hoje, muitos estudantes têm dificuldades de acesso aos programas de assistência estudantil desenvolvidos na UFPA e disponibilizados ao Campus de Altamira. Isso significa que estudantes em situação de vulnerabilidade socioeconômica, pedagógica e emocional que deveriam estar seguros em relação ao recebimento de auxílios estudantis, necessitam se submeter a processos seletivos com vagas limitadas. Em razão da alta demanda e insuficiência dos recursos disponibilizados, muitos desses estudantes apesar de terem o perfil previsto no PNAES, não conseguem obter o auxílio.

Contudo, por não atender a todos os estudantes que dependem do programa de assistência estudantil para permanecer no ensino superior e pelo fato de que a cada ano o estudante precisa solicitar a renovação de seu auxílio, sem ter a garantia de sua concessão ao longo da graduação; a assistência estudantil não assumiu um caráter de direito constitucionalmente garantido, permanecendo assim seu caráter assistencialista.

\section{CONSIDERAÇÕES FINAIS}

A trajetória da assistência estudantil no Brasil foi marcada por diferentes contextos econômicos e políticos que influenciaram seu percurso até sua institucionalização em 2010, como política de Estado. No decorrer desse processo a Assistência Estudantil foi desenvolvida por meio de ações esparsas e pontuais, vindo a ganhar notoriedade lentamente na medida em que foi sendo inserida nas legislações, mas, sobretudo como resultados das reivindicações de movimentos estudantis em prol de uma universidade pública igualitária e de qualidade.

Atualmente o PNAES se configura como uma importante política pública com vistas a alcançar os objetivos de democratização da permanência no ensino superior proposto pelo PNE para o decênio 20012010, pelo REUNI em 2007 e renovados pelo atual Plano Nacional de Educação, com vigência para o decênio 2014-2024.

Entretanto, a efetivação do PNAES no âmbito das universidades e especificamente no Campus de Altamira não alcança a todos os estudantes 
que precisam dos auxílios e não tem sido suficiente para combater os altos índices de evasão e retenção no campus, pois sua operacionalização é feita por meio de processos seletivos que excluem ao tentar incluir, em função da burocratização para solicitação de auxílio e insuficiência de recursos em relação à demanda, o que contribui para manter o caráter assistencialista da assistência estudantil.

Ressalta-se que apesar das fragilidades que envolvem a operacionalização do PNAES, ele é relevante para garantir a muitos jovens pertencentes às classes populares que antes eram excluídas do ensino superior, condições, mesmo que mínimas, de permanecer nas universidades públicas federais.

\section{REFERÊNCIAS}

ADACHI, A. A.C. T. Evasão e evadidos nos cursos de graduação da Universidade Federal de Minas Gerais. 2009. (Mestrado em Educação) Faculdade de Educação, Universidade Federal de Minas Gerais, Belo Horizonte, 2009.

ALMEIDA, J. B.; SCHIMIGUEL, J. A valiação sobre as causas da evasão escolar no ensino superior: Estudo de caso no curso de licenciatura em física no instituto federal do Maranhão. REnCiMA, v. 2, n. 2, p. 167-178, jul/dez 2011

ARAÚJO, R.S. de. A implantação do REUNE na Universidade Federal do Pará: Um estudo de caso do Campus Universitário de Altamira. Dissertação (Mestrado) Universidade Federal do Pará, Programa de Pós-Graduação em Educação, Belém, 2011.

BARDIN, L. Análise de Conteúdo. Edição revisada e atualizada. Editora 70, 2011.

BRASIL. Decreto $\mathrm{n}^{\circ} \mathbf{2 0 . 5 5 9}$, de 23 de outubro de 1931. Dispõe sobre a aplicação dos valores oferecidos pelo povo, com o intuito de auxiliar o resgate da divida externa. Rio de Janeiro, 1931. Disponível em http://www2.camara.leg.br/legin/fed/decret/1930-1939/decreto-20559-23outubro-1931-51171 1-publicacaooriginal-1-pe.html. Acesso em 10/12/2017.

BRASIL Constituição (1934). Constituição da República Federativa do Brasil: promulgada em 16 de julho de 1934. Brasília, 1934. Disponível em: <http://www.planalto.gov.br/ccivil_03/constituicao/constituica034.htm>. Acesso em: 28/11/ 2017. 
BRASIL Constitução (1946). Constituição dos Estados Unidos do Brasil: promulgada em 18 de setembro de 1946. Brasília 1946. Disponível em: < http://www.planalto.gov.br/ccivil_03/constituicao/constituicao46.htm>. Acesso em: 28/11/2017.

BRASIL lei n 4.024, de 20 de dezembro de 1961. Fixa as Diretrizes e Bases da Educação Nacional. Diário Oficial da República Federativa do Brasil .Brasília, 1961. Disponível em:< http://www.planalto.gov.br/ccivil_03/leis/L4024.htm>. Acesso em: 28/11/2017.

BRASIL Lei n 4.464, de 9 de novembro de 1964. Dispõe sobre os Órgãos de Representação dos Estudantes e dá outras providências. Brasília, 1964. Disponível em:<http://www.planalto.gov.br/Ccivil_03/leis/19501969/L4464.htm>. Acesso em: 28/11/2017.

BRASIL Constitução (1988). Constituição da República Federativa do Brasil. texto constitucional promulgado em 5 de outubro de 1988, com as alterações adotadas pelas Emendas constitucionais ns 1/1992 a 96/2017, pelo Decreto legislativo $n^{\circ} 186 / 2008$ e pelas Emendas constitucionais de revisão ns 1 a 6/1994. - 52. ed. - Brasília: Câmara dos Deputados, Edições Cômara, 2017.

BRASIL Lei n. 10.172, de 09 de janeiro de 2001. Estabelece o Plano Nacional de Educação 2001-2010. Brasília, 2001. Disponível em:

<http://www.planalto.gov.br/ccivil_03/leis/leis_2001/110172.htm>. Acesso em: 18 de maio de 2017.

BRASIL Decreto $\mathbf{n}^{\circ}$ 6.096, de 24 de abril de 2007. Institui o Programa de Apoio a Planos de Reestruturação e Expansão das Universidades Federais - REUNI. Brasília, 2007. Disponível em: < http://www.planalto.gov.br/ccivil_03/_ato20072010/2007/decreto/d6096.htm>. Acesso em de abril de 2017.

BRASIL Ministério da Educação, Secretaria de Educação Superior; Diretoria de Desenvolvimento das Instituições Federais de Ensino Superior. Programa de Apoio a Planos de Reestruturação e Expansão das Universidades Federais - Reuni 2008 - Relatório de Primeiro Ano. Brasil, 2009.

BRASIL Decreto $\mathbf{n}^{\circ} \mathbf{7 2 3 4}$, de 19 de julho de 2010. Dispõe sobre o Programa Nacional de Assistência Estudantil-PNAES. Brasília, 2010. Disponível em: <http://www.planalto.gov.br/ccivil_03/_Ato20072010/2010/Decreto/D7234.ht m.> Acesso em: 07/07/2017.

BRASIL Lei $n^{\circ}$ 12.711, de 29 de agosto de 2012. Dispõe sobre o ingresso nas universidades federais e nas instituições federais de ensino técnico de nível médio e dá outras providências. Disponível em:< http://www.planalto.gov.br/ccivil_03/_ato2011-2014/2012/lei/l12711.htm >. Acesso em: 12/11/2017. 
BRASIL Lei n 13.005, de 25 de junho de 2014. Aprova o Plano Nacional de Educação - PNE e dá outras providências. Disponível em: < http://www.planalto.gov.br/ccivil_03/_ato2011-2014/2014/lei/l13005.htm>. Acesso em: 15/11/2017.

BRASIL. Instituto Nacional de Estudos e Pesquisas Educacionais A nísio Teixeira. Relatório do $1^{\circ}$ ciclo de monitoramento das metas do PNE: Biênio 2014-2016. Brasilia, DF: Inep, 2016.

BRASIL Ministério da Educação. MEC libera R\$ 1,2 bi para instituiçõese garante custeio da Assistência Estudantil para 2017. In: Portal do MEC. Brasil, 2017. Disponível em: <http://portal.mec.gov.br/component/tags/tag/32725> Acesso em: 30/01/2018.

CARVALHO, C. H. A. de. Políticas de Expansão da Educação Superior nos Governos Democráticos Brasileiros. In:SOUZA, J. V. de (org). Expansão e Avaliação da Educação Superior Brasileira: Formatos, desafios e novas configurações. 1 ed., Belo Horizonte, MG: Fino Traço/Faculdade de Educação da Universidade de Brasília, 2015a.

CARVALHO,D. D. A. de. A Política de Assistência Estudantil da UFT: Entreo direito à permanência e a focalização do atendimento. In: CARVALHO, R. F. de (org.). Educação superior, formação e trabalho educativo. Goiânia: Ed. da PUC Goiás, 2015b.

CASTRO, R. C. A. M. Políticas de assistência estudantil, permanência e evasão no ensino superior: uma pauta em debate. II JORNEDUC - II JORNADA IBEROAMERICANA DE PESQUISAS EM POLIITICAS EDUCACIONAIS E EXPERIÊNCIAS INTERDISCIPLINARES NA EDUCA ÇÃO. Anais [...]. Instituto Federal de Educaçã̃o. Natal, RN, 2017.

CASTRO, R. C. A. M; SILVA, L. P. Indicadores educacionais no contexto do Reuni: análise na Universidade Federal do Pará. Artigo apresentado no Seminário de pesquisa PIBIC 2017. Universidade Federal do Pará, Campus Altamira, 2017.

CORREIA NETO, J. V. Registros de Vivência em República Universitária/C.E.U (Casa do Estudante Universitário): Juventude, A cesso e Permanência no Ensino Superior. Monografia (Trabalho de Conclusão de Curso), Universidade Federal do Pará Campus Altamira. Altamira, 2016.

DUTRA, N. G. dos R.; SANTOS, M. de F. de S. Assistência estudantil sob múltiplos olhares: a disputa de concepções. In: Ensaio: aval. pol. públ. Educ., Rio de Janeiro, v.25, n. 94, p. 148-181, jan./mar. 2017.

FONAPRA CE. Plano Nacional de Assistência Estudantil, 2007. FONAPRACE, 2007. Disponível em:

<http://www.andifes.org.br/wpcontent/files_flutter/Biblioteca_071_Plano_Nac 
ional_de_Assistencia_Estudantil_da_Andifes_completo.pdf >. Acesso em: 20/07/2017.

FONAPRACE. Perfil Socioeconômico e Cultural dos Estudantes de Graduação das Universidades Federais Brasileiras. FONAPRACE-2011. Disponível em: $<\mathrm{http}$ ://www.andifes.org.br/wpcontent/files_flutter/1377182836Relatorio_do_p erfi_dos_estudantes_nas_universidades_federais.pdf $>$. Acesso em: 20/08/2017.

FONAPRACE. Fórum Nacional de Pró-reitores de Assuntos Comunitários e Estudantis: Revista Comemorativa 25 Anos: histórias, memórias e múltiplos olhares. ANDIFES. - UFU, PROEX: 2012. Disponível em:

$<\mathrm{http}: / /$ www.assistenciaestudantil.cefetmg.br/galerias/arquivos_download/R evista_Fonaprace_25_Anos.pdf>. Acesso em: 20/07/2017.

$\mathrm{KÖCHE}$, J. C. Fundamentos de metodologia científica, teoria da ciência e prática da pesquisa. Petrópolis, Vozes, 2011.

LADEIRA, M.R. A.; MARTINS, R. A. de S. Limites e possibilidades para a permanência no Ensino Superior Público: o compromisso social da Universidade. In: I Congresso Internacional de Política Social e Serviço Social: Desafios Contemporâneos. Londrina PR, de 09 a 12 de Junho de 2015. Disponível em:

<http://www.vel.br/pos/mestradoservicosocial/congresso/anais/Trabalhos/ei xol/oral/12_limites_e_possibilidades....pdf > . Acesso em: 15/11/2017.

MACIEL, C. E. ; SILVA, M. das G. M. da; VELOSO T. C. M. A. Assistência Estudantil: a Evolução de uma Política Pública e os Significados no Contexto da Educação Superior. In: SOUSA, J. V. de (org.). Expansão e Avaliação da Educação Superior Brasileira: Formatos, desafios e novas configuraçōes. 1 ed. Belo Horizonte, MG: Fino Traço, Faculdade de Educação da Universidade de Brasília, 2015.

PINHEIRO, E. B. A Política Nacional de Assistência Estudantil na Universidade Federal do Pará (UFPA): A Perspectiva de Atuação da Equipe Multiprofissional no Atendimento aos discentes, XIV Colóquio Internacional de Gestão Universitária - CIGU. Santa Catarina. 2014. A cesso em: 10/06/2017.

PINHEIRO, E.B. Permanência na Universidade e a Política de Assistência Estudantil na UFPA: programas de assistência estudantil, Revista PET Interdisciplinar e Programa Conexões/UFPA On-line. Vol. 01 - 2016, p. 97- 103. Acesso em 16/11/ 2017.

RIBEIRO, D. L.; SILVA, L. P.; CASTRO, R. C. A. M. Produções teóricas sobre as políticas de ssistência estudantil implementadas na Universidade Federal do Pará. IV CONGRESSO NACIONAL DE EDUCAÇÃO, CONEDU. Anais [...], Universidade Federal da Paraíba, Joaão Pessoa, 2017.

SAMPAIO, B. et al. Desempenho no vestibular, background familiar e evasão: evidencias da UFPE. Economia Aplicada, v. 15, n. 2, p. 287-309, 2011. 
SILVA, J. K. S. da; et. al. A Assistência Estudantil na UFPA - Campus

Universitário de Altamira: Primeiras Aproximações, Jornada Internacional de Educação Paraense-JIEP. Tucuruí, 2017. A cesso em: 10/05/2017.

SOUZA, B. M. de. CASTRO, R. C. A. M. A evasão no curso de Pedagogia da UFPA, campus Altamira. ANAIS DO XXI EPEPE, Tucuruí, Pará, 2016.

SOUZA, B. M. de. A evasão no ensino superior: suas causas indicadas por estudantes de Pedagogia. Trabalho de Conclusão de Curso apresentado à Faculdade de educação da Universidade Federal do Pará, Campus de Altamira, para obtenção do grau de licenciada em Pedagogia. Altamira, 2017.

TEIXEIRA, V. da C. Evasão do estudante na Universidade Federal do Pará. Trabalho de Conclusão de Curso apresentado à Faculdade de educação da Universidade Federal do Pará, Campus de Altamira, para obtenção do grau de licenciada em Pedagogia. Altamira, 2016.

UFPA, C. U. Resolução n. 629, de 24 de outubro de 2007. Aprova a adesão da UFPA ao Programa de Apoio a Planos de Reestruturação e Expansão das Universidades Federais - REUNI. UFPA, 2007. Disponível em:

<http://www.ufpa.br/sege/boletim_interno/downloads/resolucoes/consun/20 07/Microsoft\%20Word\%20-\%20629.pdf>. A cesso em: 04/1 1/ 2017.

UFPA, C. U, PROEX. Relatório PROEX 2007: integrar desenvolver emancipar. UFPA, 2008a. Disponível em: < http://proex.ufpa.br/DIRETORIO/DOCUMENTOS/PROEX/RelatoriosA nuais/02Relat\%C3\%B3rio\%20Proex\%202007.pdf>. A cesso em: 28/1 1/2017.

UFPA, C. U, PROEX. Relatório de Gestão do Exercício de 2008. UFPA, 2008b. Disponível em:

<http://proex.ufpa.br/DIRETORIO/DOCUMENTOS/PROEX/RelatoriosA nuais/03Relat\%C3\%B3rio\%20Proex\%202008b.pdf>. Acesso em: 28/11/2017.

UFPA, C. U, PROEX. Relatório Anual de Atividade: na ilharga da universidade 2009. UFPA, 2009. Disponível em:

<http://proex.ufpa.br/DIRETORIO/DOCUMENTOS/PROEX/RelatoriosA nuais/04Relat\%C3\%B3rio\%20Proex\%202009.pdf.>. A cesso em: 28/11/2017.

UFPA, C. U. Portaria 265/2013. A prova o Projeto de extensão Assistência estudantil e Assessoramento Pedagógico. Altamira, 2013.

UFPA, C. U, PROPLAN. Plano de Desenvolvimento Institucional (PDI), 2016/2025. UFPA, 2016a. Disponível em:

<https://portal.ufpa.br/docs/PDI\%202016\%202025.pdf>. Acesso em: $30 / 05 / 2017$.

UFPA, C. U. SAEST. Indicativo de estudantes por auxílio no Campus Altamira. UFPA, $2016 \mathrm{~b}$. 
UFPA, C. U. SAEST. Resolução n. 763, de 20 de outubro de 2017. Aprova o Regimento da Superintendência de Assistência Estudantil (SAEST) da Universidade Federal do Pará. UFPA, 2017. Disponível em:

<http://www.ufpa.br/sege/boletim_interno/downloads/resolucoes/consun/20 17/763_A prova\%200\%20Regimento\%20da\%20SAEST.pdf>. Acesso em: 30/06/2017.

ZAGO, N.; PEREIRA, T.I.; PAIXÃO, L. P. Expansão do ensino superior: problematizando o acesso e a permanência de estudantes em uma nova universidade federal. $37^{a}$ Reunião Nacional da ANPEd - 04 a 08 de outubro de 2015, UFSC - Florianópolis. Disponível em:<http://www.anped.org.br/sites/default/files/trabalho-gt 14-3932.pdf>. Acesso em: 02/06/2017.

VARGAS, M. de L. F. Ensino superior, assistência estudantil e mercado de trabalho: um estudo com egressos da UFMG. Dissertação de Mestrado apresentado no Programa de Pós-Graduação em Educação da Universidade Federal de Minas Gerais. Belo Horizonte: UFMG/ FaE, 2008. Disponivel em:

<http://www.bibliotecadigital.ufmg.br/dspace/bitstream/handle/1843/FAEC84VHVQ/disserta_o_michely_vargas.pdf?sequence=1>. Acesso em: 05/01/2018.

Recebido em: 03 de fevereiro de 2018. Aprovado em: 10 de abril de 2019. 